\title{
Extra-Esophageal Manifestations of Gastroesophageal Reflux Disease: Controversies Between Epidemiology and Clinic
}

\author{
Hamid Saber ${ }^{1}$ and Mostafa Ghanei ${ }^{*}, 2$ \\ ${ }^{I}$ Faculty of medicine, Mashhad University of Medical Sciences, Mashhad, Iran \\ ${ }^{2}$ Research Center of Chemical Injuries, Baqiyatallah University of Medical Sciences, Tehran, Iran
}

\begin{abstract}
Gastroesophageal reflux disease (GERD) is widely associated with asthma, chronic cough, and laryngitis. Many studies have focused on acidic reflux; however, acid is just one of many factors that can cause pulmonary injury. The discrepancy between the high frequency of GERD in asthmatic patients and the ineffective reflux therapy outcomes in these patients suggests that GERD may cause injury through other mechanisms, such as pepsinogen, pepsin, bile salts, or other components of reflux materials, instead of the acid. Research using appropriate and innovative methodologies to investigate these potential inflammatory agents in patients with GERD is required to determine the underlying factors associated with pulmonary disorders in these patients.
\end{abstract}

Keywords: Gastroesophageal reflux disease, respiratory, asthma, cough, epidemiology.

\section{INTRODUCTION}

Gastroesophageal reflux disease (GERD) is a common problem caused by the reflux of gastric contents into the esophagus that can lead to esophageal and extraesophageal manifestations. Extraesophageal reflux syndromes involve several areas, including lung (asthma, chronic cough, bronchiolitis obliterans, pneumonia, and fibrosis), otolaryngological syndromes (laryngitis, otitis, polyps, and cancer of the larynx), chest pain, and oral and dental erosions. Respiratory disorders are among the most challenging extraesophageal syndromes of GERD. Epidemiological studies have revealed that respiratory problems, such as asthma and cough, are more likely to occur in patients with GERD than in healthy subjects [1]. However, the cause-and-effect association between respiratory disorders and GERD is controversial because each may induce the other.

GERD may cause these symptoms by a direct mechanism via aspiration and an indirect neurally mediated mechanism [2-5].

A disturbance of the normal protective mechanisms may allow direct contact of gastroduodenal contents with the larynx or airway

Defective protective mechanisms may lead to put in contact gastroduodenal contents with respiratory tissues (direct irritation). Reflux may also stimulate a vagal reflex arc producing cough and/or bronchospasm. On the other

\footnotetext{
*Address correspondence to this author at the Baqiyatallah University of Medical, Sciences, Research Center of Chemical Injuries, P.O. Box: 19945546, Tehran, Iran; Tel: +98 21 88600067; Fax: +98 21 88211524;

E-mail:mghanei@hbi.ir
}

hand, asthma or cough episodes can stimulate reflux by producing a negative intrathoracic pressure that overcomes the lower esophageal sphincter (LES) barrier. Moreover, asthma medications, such as theophylline, beta 2-agonists or prednisone, have been found to possibly increase GERD by interfering with respiratory protective mechanisms.

Animal studies have demonstrated that tissue injuries may be initiated by gastric or duodenal materials (pepsinogen, trypsin, and bile acids [3-5]) even in the absence of an acid medium [6]. Therefore, nonacidic reflux may cause tissue changes and symptoms that may not be adequately covered by proton pump inhibitors (PPIs). This rationale is hold by the marked improvement of GERDassociated pulmonary symptoms by surgical procedures as well as the evidence derived from recent functional monitoring systems support this thesis [7-9].

Response to PPI therapy is most often used for diagnosis of GERD in these patients. Although GERD is multifactorial, it is actually a motility disorder, and impaired LES function has a major role [10]. Despite the fact that epidemiological studies support a remarkable association between GERD and pulmonary symptoms of reflux, response to PPI therapy has shown diverse results and is not promising. The discrepancy between epidemiological studies and clinical trials with PPIs has not been well investigated. However, interpretation of the results based only on therapeutic clinical acid-suppressive trials is under question because GERD is a motility disorder, and nonacidic reflux secondary to GERD may still provoke respiratory problems. The purpose of this review is to explore the reasons for this discrepancy, highlighting the neglected role of non-acidic refluxate in these clinical trials with an emphasis on asthma and cough. 


\section{PATHOPHYSIOLOGIC ROLES OF NON-ACIDIC RE- FLUX IN EXTRA-ESOPHAGEAL MANIFESTATIONS OF GERD}

As mentioned above, many studies have focused on acidic GERD. The discrepancy between the high frequency of GERD in asthmatic patients and the low effectiveness of acid-suppressive treatments on asthmatic symptoms may suggest that GERD can exert its effects through mechanisms other than excessive acid production and/or that asthma per se can lead to GERD. Acid suppression and PPI therapy can change acidic reflux to nonacidic reflux, but in fact, they do not resolve reflux that can still produce respiratory symptoms [11]. Aspiration of gastric contents, such as pepsinogen, pepsin, pancreatic enzymes, and bile acids/salts, has also been reported to cause respiratory symptoms in asthmatic patients $[12,13]$. Bronchial epithelial cells of patients that are under treatment with PPIs have been shown to promote elevated IL-8 production in response to gastric content exposure. These data suggest that the refluxe in patients treated with PPIs may still induce pulmonary inflammatory responses that may even be induced in response to microbial agents or endotoxins in gastric content [14]. However, few studies have examined the role of nonacidic reflux on respiratory epithelium. Moreover, the constituents of gastric contents that have the most deleterious consequences on the respiratory epithelium have not yet been identified.

Pepsin can induce the production and release of inflammatory mediators and receptors in hypopharyngeal tissues under nonacidic conditions, which shows that pepsin may be associated with laryngeal epithelial inflammation during the course of nonacidic GERD in patients treated with high-dose PPI [15]. Pepsin may enter epithelial cells by endocytosis and cause Golgi complex and mitochondrial damage as well as interfere with gene expression pathways that are implicated in cell toxicity. Irreversible inhibition of peptic activity seems to prevent at least some of these changes. Pepsin can even lead to tissue injury at a $\mathrm{pH}$ of 7 after reactivation in epithelial cell [16]. In a study by Patterson et al., the authors reported that gastric contents in the esophagus in patients with asthma and chronic cough facilitated the release of substance $\mathrm{P}$ and neurokinin $\mathrm{A}$ into the lungs thus causing an inflammatory response in the respiratory epithelium [17]. Moreover, esophageal distention may induce neurogenic reflexes that can result in neurogenic airway inflammatory responses [13]. Improvement of respiratory symptoms following fundoplication and other surgical treatments indirectly supports this idea [18].

\section{ASTHMA AND GERD}

Epidemiology. In the last decades, many efforts have been made to identify a possible association between GERD and asthma. GERD prevalence in patients with asthma has varied widely in different populations, ranging from $30 \%$ to $90 \%[19,20]$. In a systematic review that examined 28 studies, a $59.2 \%$ weighted-average prevalence of GERD symptoms was observed in patients with asthma, while only $38.1 \%$ of controls had these symptoms [21].

A very careful study reported by Sontag et al. [22] demonstrated a higher frequency and severity of daytime and nighttime reflux symptoms in asthmatic patients than in appropriate controls. In Norway, a recent cohort study in 58,000 subjects reported that asthmatic patients were about $60 \%$ more likely to show GERD symptoms than were controls after adjustment for confounding factors [odds ratio (OR), 1.6 [23]. Another study in the UK demonstrated that the risk for asthma is increased in the years after the diagnosis of GERD (OR, 1.4; 95\% CI, 1.0-2.1) [24]. More recently, DiMango et al. demonstrated that asthmatic patients with GERD had lower asthma-related quality of life than did patients without GERD [25].

Temporal correlation between GERD and asthmatic symptoms is another important aspect that seems to reinforce the theory. In fact, such an association between pulmonary symptoms and acid reflux events detected by esophageal $\mathrm{pH}$ testing has been reported in 46 to $78 \%$ of patients with asthma. Consequently, if reflux triggers asthma, which in turn increases reflux episodes, a pathological circular effect may cause worsening or prolongation of asthmatic symptoms.

Diagnosis. The results of many studies using acid suppression strategy in asthmatic patients are not comparable since GERD has been identified on the basis of different mechanisms, such as clinical manifestations, $\mathrm{pH}$ monitoring, or both [26,27]. The follow-up period, type and dosage of acid-suppressive drugs were also different in these studies. Other confounding aspects when analyzing the literature include the different target endpoints (improvement of symptoms, peak flow meter, PFTs, and quality of life) evaluated in the studies.

Medical treatment of GERD in asthma. One method to establish a cause-effect relationship between GERD and asthma is to demonstrate improvement in symptoms following acid-suppressive therapy. Numerous clinical trials have examined the effects of PPI therapy on asthma. Several studies have observed an improvement of asthma symptoms after acid-suppressive therapy [28,29]. In a large study of 207 asthmatic patients with GERD symptoms, the authors concluded that fewer cases developed exacerbation of asthma following treatment with lansoprazole than following treatment with placebo ( $8 \mathrm{vs} 22$ patients, respectively; $P=$ $0.05)$ [30]. In another study, 15 asthmatic patients (27\%) with GERD treated with omeprazole showed a $20 \%$ improvement in forced expiratory volume in the first second $\left(\mathrm{FEV}_{1}\right)$ while only $9 \%$ did so in the control group [31]. Levin et al. reported an improvement of peak expiratory flow (PEF) rate in 9 asthmatic patients with GERD after omeprazole treatment for 8 weeks [32]. In a double-blind randomized study in 25 patients with asthma and GERD, a statistically significant improvement in evening PEF rate was observed following treatment with omeprazole compared with placebo $(P=0.05)$ [33]. In contrast, in a controlled study in 11 asthmatic patients with GERD and nocturnal asthma, low-dose PPI (20 mg/day) did not improve asthma symptoms or PEF [34]. Another study in 36 asthmatic patients with GERD and chronic obstructive pulmonary disease reported no improvement in PFTs results or respiratory symptoms following treatment with omeprazol [35]. In a systematic review by Gibson et al. [36] using 12 randomized placebo-controlled trials and the Cochrane methodology, no significant improvement in asthmatic symptoms was found after acid-suppressive therapy in 
GERD patients. In another randomized placebo-controlled study in 207 patients with asthma and GERD symptoms, lansoprazole $30 \mathrm{mg}$ b.i.d for 24 weeks reduced asthmatic exacerbations but did not dramatically improve asthma symptoms and PFTs. It should be considered that patients with moderate to severe GERD were excluded regarding their need for antireflux treatment. Mastronarde et al. [37] demonstrated that PPI treatment did not improve asthmatic symptom control in patients with refractory asthma and silent reflux.

Only 2 studies have shown a significant improvement in peak flow values $[27,38]$.

Data from a recent randomized, double-blind, controlled study by the American Lung Association Asthma Clinical Research Centers revealed that esomeprazole therapy b.i.d for 6 months did not improve control of asthma in patients with refractory asthma and silent reflux [37]. In this study that used ambulatory $24-\mathrm{h} \mathrm{pH}$ monitoring before initiation of acid suppression, about $40 \%$ of the patients had reflux but did not show clinical significant response to PPI therapy. One limitation, however, was that the role of nonacidic reflux was disregarded in this trial.

In children, the situation is quite similar to adults. Although 2 studies have reported very good results in children [39,40], Stordal et al. [41], in a double-blind randomized trial, concluded that acid-suppressive treatment in asthmatic children with GERD did not improve asthmatic symptoms These variations may partly justify the inconsistency of the results.

Surgical treatment of GERD and asthma. Many uncontrolled studies have suggested that surgery for GER might offer beneficial effects on certain outcomes of asthma. Irwin et al. [42] demonstrated that fundoplication could significantly improve asthmatic control in patients who did not initially respond to acid suppression.

The value of surgical treatment is probably related to the control of any sort of GERD, including both acidic, nonacidic, and bile reflux. Sontag et al. [22] compared the effects of fundoplication, ranitidine, and placebo on asthmatic manifestations in asthmatic patients with GERD. They concluded that $74.9 \%$ of patients showed improvement in asthmatic symptoms following surgery compared with those of $9.1 \%$ of patients who received medical treatment with ranitidine and only $4.2 \%$ of the patients in the control group.

\section{CHRONIC COUGH AND GERD}

Epidemiology. Chronic cough is one of the most common clinical presentations in primary care practice [43]. It is believed that cough is common in both erosive $(30.5 \%)$ and nonerosive (34.9\%) GERD [44].

An epidemiological association between gastric reflux and chronic cough has been demonstrated in patients of all ages [45]. However, the major limitation of many of these studies is that patients with reflux-associated cough may have silent GERD and not show GERD symptoms.

Diagnosis. Recently, the $\mathrm{pH}$ threshold has also been questioned because weakly acidic reflux has been reported to be responsible for symptoms and cough in asthmatic patients off and on acid-suppressive therapy. As it occurs with asthma, esophageal $\mathrm{pH}$ monitoring has been used to examine the association between cough and reflux in these patients.

The impact of esophageal motility defects, such as ineffective motility and delayed esophageal clearance, has been examined in chronic cough. In regard to reflex mechanisms, higher cough sensitivity following acid perfusion into the distal part of the esophagus was shown in patients with GERD and cough than in patients with GERD and no cough [46]. Topical esophageal anesthesia with lidocaine has also been shown to block acid-induced cough [47]. In a study in Wistar rats, stimulation of the esophagus with pepsin and acid led to higher c-Fos gene expression in the medulla, suggesting that acid and pepsin stimulation of the distal esophagus may cause cough-center stimulation [48]. It should be mentioned that cough and reflux may worsen each other in a circular manner that could result in more prominent manifestations.

Medical treatment of GERD in chronic cough. Treatment of cough-related reflux has been examined in many trials of acid-suppressive drug therapy and surgery, most of which have had limitations, such as small sample size, and shown inconsistent results that have made it hard to draw conclusion on the basis of their results.

In a study in patients with reflux and chronic cough, just 1 of 8 patients responded to treatment with omeprazole while none of the 9 individuals in the placebo group had such a response [49]. Kiljander et al. reported the results of their study in 29 asthmatic patients with positive 24-h $\mathrm{pH}$ monitoring test findings that showed significant improvement with omeprazol [50]. In a recent study, however, Baldi et al. [51] found that there was no difference in improvement of cough symptoms in asthmatics with GERD between different doses of lansoprazole.

In another recent trial using medical treatment with omeprazole, Vaezi et al. [52] reported complete improvement of cough symptoms in 10 of 11 cases with GERD following a 2-month period. However, most other trials have not shown significant improvement of chronic cough following treatment with acid-suppressive medical therapy [53], suggesting that factors other than the acidic content of the refluxate can be considered in patients that show no response to PPIs and that the role of nonacidic reflux in these individuals should be investigated. In addition, results from a meta-analysis of randomized controlled trials of chronic cough patients with GERD that compared PPI therapy with placebo over a 3-month period demonstrated no significant improvement in cough symptoms between PPI and placebo (odds ratio $=0.46 ; 95 \%$ CI, 0.19-1.15). New therapeutic strategies should be proposed that target both acidic and nonacidic reflux in patients with resistant cough.

Surgical treatment of GERD in chronic cough. In patients with documented correlation between GERD and cough who had no response to acid-suppressive treatment, antireflux surgery has yielded encouraging results, suggesting the presence of nonacidic reflux despite PPI therapy [11]. Outcome controlled studies of antireflux surgery in asthmatic patients with cough are required to 
elucidate the value of surgery in individuals who do not respond to PPI therapy.

\section{OTHER PULMONARY MANIFESTATIONS ASSOCI- ATED WITH GERD}

Several other pulmonary disorders have been supposed to be related to GERD. Epidemiological studies in these patients have demonstrated an increased risk of chronic bronchitis (OR:1.28) [1], chronic obstructive pulmonary disease (OR:1.22) [54], idiopathic pulmonary fibrosis (IPF) (OR:1.36) [54] and cystic fibrosis [55]. Moreover, GERD is more common in IPF compared with normal population [56]. Various respiratory complications of reflux have been reported in children with neurologic disorders or patients with debilitating diseases secondary to reflux [57].

Reflux episodes and bile acid aspiration in lung transplant patients have been thought to play an important role in the development of bronchiolitis obliterans syndrome (BOS) [58]. It has been demonstrated that lung recipients with bile in their BALF samples develop BOS earlier and are less likely to improve from BOS. In addition, higher levels of bile acids in BALF samples of lung transplant patients have been shown to be correlated with higher plasma IL-8 concentrations and neutrophilia in the BALF [59]. In the interesting study by Cantu et al. [60], the authors concluded that early fundoplication can significantly reduce development of BOS in lung transplant patients with GERD. GERD has been also associated with diffuse bronchiolitis and BOS-associated pneumonia in those without lung transplantation [61]. Also, GERD has been associated with poorer PFT in cystic fibrosis patients with GERD than in patients without GERD [55]. Gastric aspiration is also more prevalent in tube-fed patients and can lead to pneumonia and increased use of hospital resources [62].

\section{FACTORS CAUSING CONTROVERSIES IN THE LITERATURE}

One explanation is that the design and methodologies differed extensively among the studies because research in this area is spread over multiple disciplines. Moreover, the lack of clarification regarding manifestations actually caused by GERD, the best way of identifying these conditions, and the best treatments and course of therapy may have caused uncertain results. It is likely that patients have been diagnosed mistakenly and their asthma or cough was not a result of GERD. About $20 \%$ to $30 \%$ of individuals with GERD symptoms still suffer from their previous symptoms while on acid-suppressive treatment. Moreover, persisting reflux can be documented in about half of these cases, which proves the insufficiency of acid-suppressive therapy in these patients [63]. Again, it should be noted that acidic content of the refluxate may represent only 1 of the components involved in respiratory damage, and more specific research is required to identify the source of pulmonary inflammation, such as bile, pepsin, microbial components, and other components, in these patients.

Another explanation is that individuals with more prominent and severe reflux disease may be more likely to show considerable improvement of pulmonary manifestations following acid suppressive therapy $[64,65]$. These individuals are usually excluded ethically for safety reasons from all studies, which may contribute to a large bias in results. Moreover, it should be considered that all PPIs or empirical treatments have their own limitations, and GERD should not be simply ruled out because of insufficient response to PPI treatment. Similarly, inclusion criteria that will lead to the selection of an appropriate target group and the best therapeutic regimens have not yet been defined.

\section{NEW TARGETS FOR TREATMENTS}

The predominant mechanism of GERD is supposedly transient LES relaxations. Baclofen is an agonist of gammaaminobutyric acid (GABA), which decreases reflux frequency by decreasing frequency of LES in addition to having antitussive effects. However, its side effects have limited its use as a routine medication. Newer GABA agonists with fewer adverse effects are now under investigation and being used in a clinical trial to potentially show improvement in motility disorder in GERD patients. A new generation of antireflux therapies has targeted transient lower esophageal sphincter relaxation, which is the basic underlying cause of reflux. $\mathrm{GABA}_{\mathrm{B}}$ agonists and metabotropic glutamate receptor 5 (mGluR5) antagonists are the most remarkable drugs in this group and have been effective in decreasing reflux symptoms and episodes [66].

\section{CONCLUSIONS}

GERD is a common disorder caused by the reflux of gastric contents into the esophagus that may lead to several esophageal and extraesophageal disturbances. Most previous randomized clinical trials have targeted acid suppression, and other components of the refluxate have been largely neglected. Currently, there is a considerable body of evidence available indicating the important role of nonacidic gastric components in pulmonary inflammation and toxicity. Symptom improvement in response to surgical procedures that target the basic mechanism of reflux as a motility disorder provides support for this idea. Hence, the important question is how future studies should be designed and which methodologies should be used to obtain more accurate results on the association of GERD and respiratory problems. Definitions and outcome measures should be standardized. The presence and composition of major gastric contents should be investigated in the respiratory tracts in patients with GERD and respiratory problems specially in those that continue to have respiratory problems despite treatment with PPIs. Finally, there is a need for newer treatments that target the basic mechanism of GERD and its role in symptom improvement in these patients.

\section{CONFLICT OF INTEREST}

The authors confirm that this article content has no conflict of interest.

\section{ACKNOWLEDGEMENTS}

Declared none.

\section{REFERENCES}

[1] el-Serag HB, Sonnenberg A. Comorbid occurrence of laryngeal or pulmonary disease with esophagitis in United States military veterans. Gastroenterology 1997; 113: 755-60.

[2] Delahunty JE, Cherry J. Experimentally produced vocal cord granulomas. Laryngoscope 1968; 78: 1941-7. 
[3] Little FB, Koufman JA, Kohut RI, Marshall RB. Effect of gastric acid on the pathogenesis of subglottic stenosis. Ann Otol Rhinol Laryngol 1985; 94: 516-9.

[4] Tuchman DN, Boyle JT, Pack AI, et al. Comparison of airway responses following tracheal or esophageal acidification in the cat. Gastroenterology 1984; 87: 872-81.

[5] Vaezi MF. Sensitivity and specificity of reflux-attributed laryngeal lesions: experimental and clinical evidence. Am J Med 2003; 115 (Suppl 3A): 97S-104S.

[6] Adhami T, Goldblum JR, Richter JE, Vaezi MF. The role of gastric and duodenal agents in laryngeal injury: an experimental canine model. Am J Gastroenterol 2004; 99: 2098-106.

[7] Blondeau K, Dupont LJ, Mertens V, Tack J, Sifrim D. Improved diagnosis of gastro-oesophageal reflux in patients with unexplained chronic cough. Aliment Pharmacol Ther 2007 15;25: 723-32.

[8] Irwin RS. Chronic cough due to gastroesophageal reflux disease: ACCP evidence-based clinical practice guidelines. Chest 2006; 129: 80 S-94S

[9] Sifrim D, Dupont L, Blondeau K, Zhang X, Tack J, Janssens J. Weakly acidic reflux in patients with chronic unexplained cough during 24 hour pressure, $\mathrm{pH}$, and impedance monitoring. Gut 2005; 54: 449-54.

[10] Sifrim D, Holloway R, Silny J, Tack J, Lerut A, Janssens J. Composition of the postprandial refluxate in patients with gastroesophageal reflux disease. Am J Gastroenterol 2001; 96: 64755.

[11] Tutuian R, Mainie I, Agrawal A, Adams D, Castell DO. Nonacid reflux in patients with chronic cough on acid-suppressive therapy. Chest 2006; 130: 386-91.

[12] Asano K, Suzuki H. Silent acid reflux and asthma control. N Engl J Med 2009; 360: 1551-3.

[13] Canning BJ, Mazzone SB. Reflex mechanisms in gastroesophageal reflux disease and asthma. Am J Med 2003; 115(Suppl 3A): 45S$8 \mathrm{~S}$.

[14] Mertens V, Blondeau K, Vanaudenaerde B, et al. Gastric juice from patients "on" acid suppressive therapy can still provoke a significant inflammatory reaction by human bronchial epithelial cells. J Clin Gastroenterol 2010; 44: e230-5.

[15] Samuels TL, Johnston N. Pepsin as a causal agent of inflammation during nonacidic reflux. Otolaryngol Head Neck Surg 2009; 141: 559-63.

[16] Johnston N, Wells CW, Samuels TL, Blumin JH. Rationale for targeting pepsin in the treatment of reflux disease. Ann Otol Rhinol Laryngol 2010; 119: 547-58.

[17] Patterson RN, Johnston BT, Ardill JE, Heaney LG, McGarvey LP. Increased tachykinin levels in induced sputum from asthmatic and cough patients with acid reflux. Thorax 2007; 62: 491-5.

[18] Rakita S, Villadolid D, Thomas A, et al. Laparoscopic Nissen fundoplication offers high patient satisfaction with relief of extraesophageal symptoms of gastroesophageal reflux disease. Am Surg 2006; 72: 207-12.

[19] Harding SM, Guzzo MR, Richter JE. 24-h esophageal pH testing in asthmatics: respiratory symptom correlation with esophageal acid events. Chest 1999; 115: 654-9.

[20] Vincent D, Cohen-Jonathan AM, Leport J, et al. Gastrooesophageal reflux prevalence and relationship with bronchial reactivity in asthma. Eur Respir J 1997; 10: 2255-9.

[21] Vaezi MF. Atypical manifestations of gastroesophageal reflux disease. MedGenMed 2005; 7(4): 25.

[22] Sontag SJ, O'Connell S, Khandelwal S, et al. Asthmatics with gastroesophageal reflux: long term results of a randomized trial of medical and surgical antireflux therapies. Am J Gastroenterol 2003; 98: 987-99.

[23] Nordenstedt H, Nilsson M, Johansson S, et al. The relation between gastroesophageal reflux and respiratory symptoms in a populationbased study: the Nord-Trondelag health survey. Chest 2006; 129: 1051-6.

[24] Ruigomez A, Garcia RLA, Wallander MA, Johansson S, Graffner H, Dent J. Natural history of gastro-oesophageal reflux disease diagnosed in general practice. Aliment Pharmacol Ther 2004; 20 : 751-60.

[25] DiMango E, Holbrook JT, Simpson E, et al. Effects of asymptomatic proximal and distal gastroesophageal reflux on asthma severity. Am J Respir Crit Care Med 2009; 180: 809-16.

[26] Eherer AJ, Habermann W, Hammer HF, Kiesler K, Friedrich G, Krejs GJ. Effect of pantoprazole on the course of reflux-associated laryngitis: a placebo-controlled double-blind crossover study. Scand J Gastroenterol 2003; 38: 462-7.

[27] Shimizu Y, Dobashi K, Kobayashi S, et al. A proton pump inhibitor, lansoprazole, ameliorates asthma symptoms in asthmatic patients with gastroesophageal reflux disease. Tohoku J Exp Med 2006; 209: 181-9.

[28] Kiljander TO, Harding SM, Field SK, et al. Effects of esomeprazole $40 \mathrm{mg}$ twice daily on asthma: a randomized placebocontrolled trial. Am J Respir Crit Care Med 2006; 173: 1091-7.

[29] Sharma B, Sharma M, Daga MK, Sachdev GK, Bondi E. Effect of omeprazole and domperidone on adult asthmatics with gastroesophageal reflux. World J Gastroenterol 2007; 13: 1706-10.

[30] Littner MR, Leung FW, Ballard ED, Huang B, Samra NK. Effects of 24 weeks of lansoprazole therapy on asthma symptoms, exacerbations, quality of life, and pulmonary function in adult asthmatic patients with acid reflux symptoms. Chest 2005; 128 : 1128-35.

[31] Meier JH, McNally PR, Punja M, et al. Does omeprazole (Prilosec) improve respiratory function in asthmatics with gastroesophageal reflux? A double-blind, placebo-controlled crossover study. Dig Dis Sci 1994; 39: 2127-33.

[32] Levin TR, Sperling RM, McQuaid KR. Omeprazole improves peak expiratory flow rate and quality of life in asthmatics with gastroesophageal reflux. Am J Gastroenterol 1998; 93: 1060-3.

[33] Teichtahl H, Kronborg IJ, Yeomans ND, Robinson P. Adult asthma and gastro-oesophageal reflux: the effects of omeprazole therapy on asthma. Aust N Z J Med 1996; 26: 671-6.

[34] Ford GA, Oliver PS, Prior JS, Butland RJ, Wilkinson SP. Omeprazole in the treatment of asthmatics with nocturnal symptoms and gastro-oesophageal reflux: a placebo-controlled cross-over study. Postgrad Med J 1994; 70: 350-4.

[35] Boeree MJ, Peters FT, Postma DS, Kleibeuker JH. No effects of high-dose omeprazole in patients with severe airway hyperresponsiveness and (a)symptomatic gastro-oesophageal reflux. Eur Respir J 1998; 11: 1070-4.

[36] Gibson PG, Henry RL, Coughlan JL. Gastro-oesophageal reflux treatment for asthma in adults and children. Cochrane Database Syst Rev 2003; (2): CD001496.

[37] Mastronarde JG, Anthonisen NR, Castro M, et al. Efficacy of esomeprazole for treatment of poorly controlled asthma. N Engl J Med 2009; 360: 1487-99.

[38] Jiang SP, Liang RY, Zeng ZY, Liu QL, Liang YK, Li JG. Effects of antireflux treatment on bronchial hyper-responsiveness and lung function in asthmatic patients with gastroesophageal reflux disease. World J Gastroenterol 2003; 9: 1123-5.

[39] Khoshoo V, Le T, Haydel RM Jr, Landry L, Nelson C. Role of gastroesophageal reflux in older children with persistent asthma. Chest 2003; 123: 1008-13.

[40] Yuksel H, Yilmaz O, Kirmaz C, Aydogdu S, Kasirga E. Frequency of gastroesophageal reflux disease in nonatopic children with asthma-like airway disease. Respir Med 2006; 100: 393-8.

[41] Stordal K, Johannesdottir GB, Bentsen BS, et al. Acid suppression does not change respiratory symptoms in children with asthma and gastro-oesophageal reflux disease. Arch Dis Child 2005; 90: 95660.

[42] Irwin RS, Zawacki JK, Wilson MM, French CT, Callery MP. Chronic cough due to gastroesophageal reflux disease: failure to resolve despite total/near-total elimination of esophageal acid. Chest 2002; 121: 1132-40.

[43] Irwin RS, Corrao WM, Pratter MR. Chronic persistent cough in the adult: the spectrum and frequency of causes and successful outcome of specific therapy. Am Rev Respir Dis 1981; 123: 413-7.

[44] Jaspersen D, Kulig M, Labenz J, et al. Prevalence of extraoesophageal manifestations in gastro-oesophageal reflux disease: an analysis based on the ProGERD Study. Aliment Pharmacol Ther 2003; 17: 1515-20.

[45] Irwin RS, Richter JE. Gastroesophageal reflux and chronic cough. Am J Gastroenterol 2000; 95: S9-14.

[46] Javorkova N, Varechova S, Pecova R, et al. Acidification of the oesophagus acutely increases the cough sensitivity in patients with gastro-oesophageal reflux and chronic cough. Neurogastroenterol Motil 2008; 20: 119-24.

[47] Ing AJ, Ngu MC, Breslin AB. Pathogenesis of chronic persistent cough associated with gastroesophageal reflux. Am J Respir Crit Care Med 1994; 149: 160-7. 
[48] Shuai XW, Xie PY. Expression and localization of c-Fos and NOS in the central nerve system following esophageal acid stimulation in rats. World J Gastroenterol 2004; 10: 2287-91.

[49] Ours TM, Kavuru MS, Schilz RJ, Richter JE. A prospective evaluation of esophageal testing and a double-blind, randomized study of omeprazole in a diagnostic and therapeutic algorithm for chronic cough. Am J Gastroenterol 1999; 94: 3131-8.

[50] Kiljander TO, Salomaa ER, Hietanen EK, Terho EO. Chronic cough and gastro-oesophageal reflux: a double-blind placebocontrolled study with omeprazole. Eur Respir J 2000; 16: 633-8.

[51] Baldi F, Cappiello R, Cavoli C, Ghersi S, Torresan F, Roda E. Proton pump inhibitor treatment of patients with gastroesophageal reflux-related chronic cough: a comparison between two different daily doses of lansoprazole. World J Gastroenterol 2006; 12: 82-8.

[52] Vaezi MF, Richter JE. Twenty-four-hour ambulatory esophageal $\mathrm{pH}$ monitoring in the diagnosis of acid reflux-related chronic cough. South Med J 1997; 90: 305-11.

[53] Chang AB, Lasserson TJ, Kiljander TO, Connor FL, Gaffney JT, Garske LA. Systematic review and meta-analysis of randomised controlled trials of gastro-oesophageal reflux interventions for chronic cough associated with gastro-oesophageal reflux. BMJ 2006; 332: 11-7.

[54] Galmiche JP, Zerbib F, Bruley DV. Review article: respiratory manifestations of gastro-oesophageal reflux disease. Aliment Pharmacol Ther 2008; 27: 449-64.

[55] Stringer DA, Sprigg A, Juodis E, et al. The association of cystic fibrosis, gastroesophageal reflux, and reduced pulmonary function. Can Assoc Radiol J 1988; 39: 100-2.

[56] Tobin RW, Pope CE, Pellegrini CA, Emond MJ, Sillery J, Raghu G. Increased prevalence of gastroesophageal reflux in patients with idiopathic pulmonary fibrosis. Am J Respir Crit Care Med 1998; 158: $1804-8$
[57] Boesch RP, Daines C, Willging JP, et al. Advances in the diagnosis and management of chronic pulmonary aspiration in children. Eur Respir J 2006; 28: 847-61.

[58] Blondeau K, Mertens V, Vanaudenaerde BA, et al. Nocturnal weakly acidic reflux promotes aspiration of bile acids in lung transplant recipients. J Heart Lung Transplant 2009; 28: 141-8.

[59] D'Ovidio F, Mura M, Tsang M, et al. Bile acid aspiration and the development of bronchiolitis obliterans after lung transplantation. J Thorac Cardiovasc Surg 2005; 129: 1144-52.

[60] Cantu E III, Appel JZ III, Hartwig MG, et al. J. Maxwell Chamberlain Memorial Paper. Early fundoplication prevents chronic allograft dysfunction in patients with gastroesophageal reflux disease. Ann Thorac Surg 2004; 78: 1142-51.

[61] Matsuse T, Oka T, Kida K, Fukuchi Y. Importance of diffuse aspiration bronchiolitis caused by chronic occult aspiration in the elderly. Chest 1996; 110: 1289-93.

[62] Metheny NA, Clouse RE, Chang YH, Stewart BJ, Oliver DA, Kollef MH. Tracheobronchial aspiration of gastric contents in critically ill tube-fed patients: frequency, outcomes, and risk factors. Crit Care Med 2006; 34: 1007-15.

[63] Mainie I, Tutuian R, Shay S, et al. Acid and non-acid reflux in patients with persistent symptoms despite acid suppressive therapy: a multicentre study using combined ambulatory impedance-pH monitoring. Gut 2006; 55: 1398-402.

[64] Harding SM, Richter JE, Guzzo MR, Schan CA, Alexander RW, Bradley LA. Asthma and gastroesophageal reflux: acid suppressive therapy improves asthma outcome. Am J Med 1996; 100: 395-405.

[65] Kiljander T, Salomaa ER, Hietanen E, Helenius H, Liippo K, Terho EO. Asthma and gastro-oesophageal reflux: can the response to anti-reflux therapy be predicted? Respir Med 2001; 95: 387-92.

[66] Zerbib F. Medical treatment of GORD. Emerging therapeutic targets and concepts. Best Pract Res Clin Gastroenterol 2010; 24: $937-46$. 